\title{
Pendidikan Cinta Kasih Anak dalam Perspektif Filsafat IImu
}

\author{
Azam Syukur Rahmatullah ${ }^{1}$ \\ ${ }^{1}$ Magister Ilmu Agama Islam, Universitas Muhammadiyah Yogyakarta, Yogyakarta, Indonesia \\ E-mail: azam.sy@umy.ac.id ${ }^{1}$
}

\begin{abstract}
Abstrak
Tulisan ini membahas tentang bagaimana mendidik diri untuk menyemaikan cinta kasih kepada anak. Hal ini dikarenakan, di era modernisasi ditemukan banyak penelitian yang menyatakan tentang tindakan krisis kasih sayang terhadap anak. Maraknya kekerasan, bullying yang dilakukan oleh orang tua kepada anak-anaknya, atau dilakukan oleh orang dewasa kepada anak. Hal yang demikian tentu saja meresahkan dan memprihatinkan, di sisi lain akan menjadi beban psikologis anak di masa sekarang dan masa depan. Oleh karenanya, tulisan ini memperdalam berkaitan tentang olah rasa, olah piker, dan olah perilaku dalam mencintai dan mengasihi anak yang sesungguhnya. Pendekatan kajian yang digunakan adalah pendekatan filsafat ilmu, yang di dalamnya memuat kajian ontologis, epistimologis, dan aksiologis. Kajian ontologis nampak pada pemaparan terkait dengan apa dan mengapa tentang krisis cinta kasih kepada anak. Kemudian kajian epistimologis berkaitan dengan cinta kasih dalam tinjauan filosofi, dan juga berkaitan tentang kemengapaan cinta kepada anak ditanggalkan serta bagaimana cara mendidik diri untuk memberi cinta kasih kepada anak. Sedangkan, kajian aksiologisnya adalah tentang apa kebermanfaatan mendidik diri dalam memberi cinta kasih kepada anak. Metode penelitian ini adalah penelitian kualitatif. Hasil dari Penelitian adalah menunjukkan bahwa cinta kasih merupakan fitrah manusia yang harus dijunjung tinggi oleh siapapun. Cinta kasih yang harus "tumbuh dan berkembang" adalah cinta kasih tulus tanpa syarat kepada siapapun terutama kepada anak-anak. Cinta kasih harus dibangun melalui kultur diri dengan mendidik diri agar benar-benar tulus menyayangi dan mencintai anak-anak, dengan tidak mengedepankan kekerasan dan menjadi momok yang mencemaskan dan menggelisahkan anak.
\end{abstract}

Kata Kunci: cinta kasih; filsafat ilmu; mendidik diri.

\begin{abstract}
This paper discusses how to educate ourself to instill love for children. This is because in this modernization era, there have been many studies which state about crisis actions of affection for children. Many violence and bullying done by their children parents, or perpetrated by adults to children. This is very unsettling and cause for concern, and it will become a psychological burden for children in the present and future. Therefore, this paper explores the feeling, thought and behavior processing in loving and loving real children. The study approach used a philosophy of science approach, which includes ontological, epistemological and axiological studies. The ontological study looks at the explanation regarding what and why about the crisis of love for children, then the epistemological study related to love in a philosophical review, and also related to why love for children is abandoned and how to educate ourself to give love for children. Meanwhile, the axiological study is about the benefits of educating oneself in giving love for children. This research method is qualitative research. The results of the research are to show that love is a human nature that must be upheld by anyone. Love that must grow and develop is unconditional sincere love for anyone, especially children. Love must be built through culture. self by educating oneself to really sincerely love and love children, by not prioritizing violence and becoming a scourge that worries and worries children.
\end{abstract}

Keyword: love; philosophy of science; educate ourself.

\section{Pendahuluan}

Pada era modernisasi-teknologi, yang mana semua kemudahan bisa didapatkan, mengakibatkan cara berpikir manusia mengalami perubahan pesat. Rasionalisme dan kritisisme 
manusia semakin berkembang dan menjadi "dewa" dalam laju perjalanan hidup. Hal ini karena, para kaum rasinoalisme berasumsi bahwa akal adalah alat terpenting dalam memperoleh pengetahuan dan mengetes pengetahuan, sehingga semakin pengetahuan tumbuh subur maka teknologi pun akan tumbuh dengan pesat dan makmur. Dengan kata lain, apa yang terjadi saat ini dan terlihat secara nyata, bahwa perkembangan teknologi yang semakin kuat karena peran akal dan pemikiran kompherensif manusia nan hebat. Hal ini sesuai dengan apa yang disampaikan oleh Yanti (2017) bahwa akal tonggak kehidupan manusia dan dasar kelanjutan wujudnya, yang berarti berkembang atau maju dan mundurnya sesuatu itu salah satunya tergantung daripada peranan akal manusia dengan pengetahuan yang diramunya.

Pemberdayaan akal itu sendiri harus selaras dengan pemberdayaan cinta kasih. Akal yang melaju pesat harus diseimbangkan dengan pesatnya penanaman cinta kasih dalam diri. Manusia harus berkorban dan berjuang untuk melakukan sinergitas antara keduanya, yang menurut Mahatma Gandhi (2018) dinyatakan bahwa manusia itu harus berani melakukan pengorbanan untuk diri, karena orang-orang yang berani adalah dasar perubahan untuk menjadi lebih baik. Dalam hal ini, cinta kasih sejatinya adalah kodrati yang dimiliki oleh manusia, namun, apabila tidak bersinergi dengan akal yang sehat, maka cinta kasih tidak akan berjalan berdampingan. Akal yang rusak akan mengarahkan pada cinta kasih yang mati. Akal yang tidak berkembang positif akan mematikan rasa cinta kasih. Kondisi yang demikian akan melahirkan orang-orang yang hidup pada era emas tetapi tidak memiliki hati dan perasaan.

Kondisi yang demikian dapat dilihat dari kasus-kasus nyata di era kini yang menunjukkan jumlah peningkatan kekerasan terhadap sesama, salah satunya adalah terhadap anak-anak. Kekerasan yang dilakukan oleh orang-orang berakal sakit yang menjauhkan dari konsep welas asih atau cinta kasih. Beberapa bukti nyata adalah; Pertama, adanya pernyataan Asisten Deputi Bidang Perlindungan Anak dari kekerasan dan eksploitasi, Valentina Gintings yang mengatakan maraknya kasus kekerasan terhadap anak yang terjadi selama pandemi. "Berdasarkan data SIMFONI PPA, pada 1 Januari - 19 Juni 2020 telah terjadi 3.087 kasus kekerasan terhadap anak, diantaranya 852 kekerasan fisik, 768 psikis, dan 1.848 kasus kekerasan seksual, dan angka tersebut tergolong tinggi (Media, 2020). Kedua, Kementerian Pemberdayaan Perempuan dan Perlindungan Anak (Kementerian PPPA) menyatakan, angka kekerasan pada anak terbilang tinggi pada paruh pertama tahun 2020. Kementerian PPPA setidaknya mencatat ada 4.116 kasus kekerasan pada anak pada periode 1 Januari hingga 31 Juli 2020 (Kamil, 2020).

Bukti nyata di atas menunjukkan krisis cinta, krisis kedamaian, krisis kasih sayang. Akal yang seharusnya menjadi penerang perilaku positif, justru menjadi pemicu perilaku angkara murka. Hal tersebut dapat dikatakan bahwa cinta tertindas, cinta kasih terpasung, cinta tidak terdidik, dan tidak terhadirkan dalam diri, tidak selaras dengan idealitasnya yang menurut Plato (2017) cinta sejatinya adalah keindahan yang melahirkan keindahan. Sedangkan menurut Mo Tzu cinta adalah bagaimana memperlakukan orang lain dengan penuh kebijaksanaan sebagaimana memperlakukan terhadap dirinya sendiri. Perlu ada pemahaman yang lebih jelas supaya orang tua bisa memperlakukan anak dengan lebih baik. Pemahaman tersebut bisa dijelaskan menggunakan perspektif ilmu tertentu dan bisa dikaji secara ilmiah. Berdasarkan dari kasus tersebut, artikel ini akan membahas tentang cinta kasih terhadap anak dalam perspektif filasafat ilmu, dengan harapan akan memperjelaskan bagaimana kesejatian cinta kasih terhadap sesama terutama kepada anak-anak yang memang masih membutuhkan cinta kasih yang tulus tanpa syarat.

\section{Metode}

Tujuan dari penelitian ini adalah untuk memaparkan, menjelaskan, dan menganalisis cinta kasih anak dalam perspektif filsafat ilmu. Penelitian ini merupakan penelitian kualitatif dengan pendekatan deskriptif. Menurut Wirartha (2006) metode analisis deskriptif kualitatif adalah menganalisis dan meringkas berbagai kondisi dari berbagai data yang dikumpulkan yang berupa hasil wawancara atau pengamatan mengenai masalah yang diteliti di lapangan. Sedangkan menurut Sugiyono (2011) metode analisis deskriptif kualitatif adalah metode analisis yang berlandaskan pada filsafat pos positivisme yang digunakan untuk meneliti pada kondisi objek yang alaimah dimana peneliti adalah instrument kunci. Hasil penelitian kualitatif lebih menekankan makna daripada generalisasi.

Metode penelitian ini sering digunakan untuk meneliti kondisi obyek yang alamiah yaitu obyek yang berkembang apa adanya, tidak dimanioulasi oleh peneliti dan kehadiran peneliti tidak mempengaruhi dinamika pada objek tersebut. Dalam penelitian kualitatif, rumusan masalah 
merupakan fokus penelitian yang masih bersifat sementara dan akan berkembang setelah peneliti masuk ke dalam situasi sosial tertentu dengan maksud untuk memahami gejala sosial yang komplek.

Pendekatan kajian yang digunakan dalam penelitian ini adalah adalah pendekatan filsafat ilmu, yang di dalamnya memuat kajian ontologis, epistimologis, dan aksiologis. Ontologi adalah ilmu hakekat yang menyelidiki alam nyata ini dan bagaimana keadaan yang sebenarnya. Kajian ontologis nampak pada pemaparan terkait ada apa dan mengapa tentang krisis cinta kasih kepada anak. Epistemologi adalah ilmu yang membahas secara mendalam segenap proses penyusunan pengetahuan yang benar. Kajian epistimologis berkaitan dengan cinta kasih dalam tinjauan filosofi,dan juga berkaitan tentang kemengapaan cinta kepada anak ditanggalkan serta bagaimana cara mendidik diri untuk memberi cinta kasih kepada anak. Sedangkan, aksiologi adalah ilmu pengetahuan yang menyelidiki hakikat nilai yang ditinjau dari sudut kefislafatan. Kajian aksiologisnya adalah tentang apa kebermanfaatan mendidik diri dalam memberi cinta kasih kepada anak (Bahrum, 2013).

\section{Hasil dan Pembahasan}

\section{a. Cinta Kasih dalam Tinjauan Filosofi}

Cinta dalam kajian Filsafat menurut Aristoteles adalah gerakan yang dihasilkan di dalam jantung; saat sekali bergerak, akan berpindah dan tumbuh. Setelah itu, ketika dewasa, akan dihubungkan oleh keinginan untuk berkasih sayang. Dalam hal ini, apabila lubuk hati mendalam pecinta meningkat maka akan memunculkan ketekunan, kegembiraan, harapan, atau keinginan. Maka hal ini, akan mengarahkannya pada keinginan dan dorongan serta mengalami kesedihan yang menggelisahkan, tidak bisa tidur terus-menerus, gairah putus asa, kesedihan, dan kehancuran pikiran (Kartanegara, 2017). Plato menyebut kata cinta dengan istilah Eros disebut pula sebagai daimon yang memiliki sifat kedewaan yang hebat sebab seluruh alam dewata berada pada pertengahan antara dewa yang abadi dan sifat fana.

Adapun yang dinamakan kasih adalah keinginan untuk memuaskan hati dan mendamaikan hati diri sendiri dan orang lain. Thomas Aquinas (2019) menyatakan bahwa kasih adalah sumber kebahagiaan. Kebahagiaan itu sendiri adalah suatu keadaan yang berlangsung dan bukanlah suatu perasaan atau emosi yang berlalu. Poespoprodjo (1999) mengatakan bahwa kasih lebih tinggi posisi derajatnya daripada cinta. Jika kasih sumber utamanya adalah hati nurani (conscience) yang mana kasih ini tidak akan pernah membohongi diri dan bersifat tulus murni tanpa syarat. Hati nurani yang mencakup kasih ini adalah hati nurani yang saksama yakni hati nurani yang paham betul terhadap hal-hal yang baik dan berbuat baik, dan meninggalkan hal-hal yang buruk.

Dengan demikian cinta kasih dalam perspektif filsafat ini memuat beberapa hal; Pertama, adanya hati yang tumbuh secara positif dan berkembang dengan baik. Kedua, adanya kegembiraan yang muncul dari dalam hati, kebahagiaan itu muncul karena hati yang sedang berbahagia. Ketiga, adanya kepuasan batin yang pada akhirnya akan berimbas kepada orang lain.

\section{b. Mengapa Cinta Kasih Terhadap Anak Ditanggalkan?}

Cinta kasih adalah lahir dari sebuah ketulusan, cinta kasih hadir tanpa adanya paksaan dan menunjukkan empati, perhatian, dan pengorbanan diri (Gunawan, 2018). Idealnya cinta kasih terus ditumbuhkan dan diberdayakan dalam diri sehingga akan terus menebarkan kebermanfaatan dan kebaikan untuk sesama. Meski pada tataran realita telah ditampakkannya orang-orang yang tidak memiliki cinta dan kasih dalam diri, merebaknya orang-orang yang rendah etika yang lebih mengedepankan ego diri (Salam, 2000). Fakta dan data yang ditunjukkan oleh KPAI dan Kementerian Pemberdayaan Perempuan dan Perlindungan Anak RI, menggambarkan krisis cinta kasih dari orang-orang yang harusnya mengembangkannya. Cinta dan kasih belum dibumisasikan dalam jiwa, pikiran, dan perilaku, atau baru dalam wacana, diskusi atau pula masih sebatas teorisasi.

Hal yang menjadi pertanyaan adalah mengapa banyak orang yang menanggalkan cinta kasih terhadap anak-anaknya, dan merasa diri bahwa hal tersebut perbuatan yang sah dan tidak keliru, sehingga menjadi tradisi "untuk menyakiti anak-anak". Hal ini ada beberapa hal yang menjadi faktornya, yakni sebagai berikut.

1) Kultur nilai yang belum dibangun dalam diri. Kultur nilai ini memuat elemen pertimbangan yang membawa ide-ide seorang individu mengenai hal-hal yang benar, baik, atau diinginkan 
dalam diri. Apabila nilai sudah menjadi kultur dalam diri maka, seseorang akan tetap menghidupkan pikiran dan hatinya untuk bersanding pada kebenaran, kebaikan dalam perilaku diri sehari-hari.

2) Internalisasi moral yang belum utuh masuk ke dalam diri, masih sebatas formalitas belaka. Auguste Comte sebagai pendiri aliran positivisme, menyatakan bahwa etika, moral dianggap sebagai ilmu tertinggi. Kebisaan moral positif merupakan hasil dari internalisasi moral yang masuk ke dalam diri dan mampu diterjemahkan ke dalam diri dengan baik, sehingga perilaku yang ditampakkan tidaklah kamuflase dan bersifat sementara. Perilaku yang dimunculkan kepermukaan benar-benar lahir dari cinta dan ketulusan yang pada akhirnya mempengaruhi dalam sikap.

3) Pendekatan logika berpikir dan etika-estetika diri yang belum selaras. Logika berpikir yang masih individualistis dan menyengaja untuk tidak membentuk unsur etika-estetika diri akan menjauh dari tatanan perilaku positif dalam keseharian. Hal yang demikian akan menjauh dari kemurnian cinta kasih baik terhadap diri maupun kepada sesama. (Azam Syukur Rahmatullah, 2016).

Beberapa faktor di atas inilah yang menjadi penyebab utama maraknya orang-orang yang aniaya terhadap kaum anak dan remaja. Akibatnya, banyak anak-anak yang mengalami depresi, dan tidak terbentuk kesejahteraan diri. Di sisi lain juga mengalami kekalutan mental, trauma, dan suasana hati (steeming) yang tidak menentu. Hal tersebut berdampak pula pada lahirnya anakanak yang; Pertama, berkepribadian tidak sehat, yang sakit jiwanya. Kedua, Anak-anak yang tidak matang kepribadiannya, Ketiga, Tidak mampu berfungsi sepenuhnya, Keempat, Anak-anak yang tidak produktif, serta Kelima, anak-anak yang tidak mampu mengaktualisasikan diri dalam keseharian.

\section{c. Mendidik Diri untuk Memberi Cinta Kasih kepada Anak}

Manusia hakikatnya adalah pengembara jiwa, yang mengandung kemungkinan baik dan buruk. Manusia yang mampu menggunakan akal dan hati nuaraninya dengan bijaksana akan mengarahkan diri pada kebaikan perilaku, yang memaksimalkan potensi cinta kasih kepada sesama. Namun sebaliknya manusia yang tidak mampu menggunakan akal dan hati nuraninya dengan baik, akan membawa manusia pada jalan kesesatan yang menutupi hatinya untuk berbuat cinta dan kasih kepada sesama. Hal inilah yang menyebabkan keharusan diri untuk mendidik jiwa, mendidik hati, mendidik perilaku, mendidik perbuatan agar senantiasa berada pada tujuan yang tepat, dan tidak menyimpang.

Sumber dari segala perilaku diri adalah hati (al-qalb). Hati yang terdidik dengan ketulusan akan membawa diri pada cinta yang tulus. Hati yang terdidik dengan kemuliaan, akan membawa diri pada memuliakan, dan hati yang terdidik dengan kebaikan akan membawa diri pada keselamatan sesama yang di dalamnya kental dengan unsur cinta kasih. Dengan demikian, mendidik diri adalah bagian dari pengorbanan. Simon May (2011) menyatakan bahwa salah satu bentuk pengorbanan cinta adalah mengolah rasa, mengolah pikiran dan mengolah perbuatan agar tetap tidak berubah dan justru semakin tumbuh berkembang, yang pada akhirnya membawa pada kebaikan sesama.

Bagaimana cara mendidik diri agar tetap bisa berbagi cinta dan kasih kepada sesama terutama anak-anak, yang memang membutuhkan cinta kasih yang berlebih? Salah satu hal yang harus diperbuat untuk mendidik diri adalah dengan memahami hakikat diri sebagai manusia. Ada tiga sifat menurut Actus Humanus yakni: pengertian/pengetahuan, kesukarelaan dan kemerdekaan. Pertama, pengertian merupakan perbuatan terbit dari suatu motif dan diarahkan pada suatu tujuan. Seseiorang yang mengetahui hakikat dirinya akan mengarahkan tujuan hidupnya pada kebaikan. Kedua, kesukarelaan, agar terdapat perbuatan diri yang manusiawi tidaklah cukup ada pengertian, tetapi juga harus dikehendaki. Suatu perbuatan sukarela adalah perbuatan yang dikehendaki, yang tidak dipaksa pada si pribadi dari luar. Manusia yang mengetahui hakikat dirinya akan melakukan tindakan yang sukarela dan tulus tanpa syarat apapun. Ketiga, kemerdekaan kehendak, yakni kebebasan untuk melakukan tindakan-tindakan antara yang sukarela dan yang tidak sukarela, antara yang tulus dan yang tidak tulus, dan seseorang yang memahami hakikat dirinya akan memiliki tindakan yang memberikan dampak kebaikan kepada sesama. Agustinus W. Dewantara (2017). 


\section{d. Kebermanfaatan Mendidik Diri Dalam Memberi "Cinta Kasih" Kepada Anak}

Salah satu prinsip finalitas (Principle of Finality) bahwa setiap penindak berbuat untuk suatu tujuan (every agent acts for and end), dan apabila setiap penindak berbuat untuk suatu tujuan tersebut, maka bisa dipastikan bahwa setiap penindak manusiawi berbuat untuk suatu tujuan. Manusia hakikatnya adalah sebagai penindak, yang memiliki tujuan, dan akan berupaya berbuat untuk meraih tujuan. Salah satu tujuan sebagaimana dijelaskan di awal adalah mendidik diri untuk menggapai cinta kasih diri yang harapannya mampu membawa diri pada kesejahteraan diri dan sesama.

Pendidikan diri cinta kasih terutama kepada anak, sejatinya tujuan dan sesuatu yang baik yang tertinggi, dan bertujuan akhir adalah satu dan sama untuk sesama, yakni sama-sama ingin merasakan kebahagiaan, kebersamaan, kedamaian, keharmonisan, dan kesejahteraan. Kesemua itu merupakan kebaikan moralnya dan tujuan terakhir. Oleh karenanya, pendidikan diri untuk memberikan cinta kasih kepada sesama terutama anak, memiliki banyak kebermanfaatan, yakni sebagai berikut.

Pertama, Meluruskan perilaku diri. Dengan hati yang terus terdidik karena hati merupakan sumber perilaku, dengan pikiran yang terus ter-asah positif, maka harapannya cinta kasih diri akan terbangun dengan baik dan akan tetap lurus memberikan kebermanfaatan bagi sesama. Manakala diri tidak terdidik maka dikhawatirkan perilaku diri akan menyimpang dari jalan kebenaran.

Kedua, Menuju manusia yang berfungsi sepenuhnya. Rogers (1991) menyatakan bahwa manusia yang mampu berfungsi sepenuhnya adalah manusia yang kaya akan pengertian diri, dan pemahaman diri. Dengan mendidik diri harapannya keberfungsian diri sepenuhnya yang di dalamnya memuat pengertian dan pemahaman diri dapat diraih dengan baik.

Ketiga, Membangun kultur kebaikan dan kebajikan dalam diri. Dengan mendidik diri akan cinta kasih sejatinya adalah sedang membangun kultur kebaikan dan kebajikan dalam diri yang pada akhirnya akan disemaikan kepada orang lain, dan arahnya adalah menuju being value, yakni manusia yang bermakna..

\section{Simpulan dan Saran}

Cinta kasih merupakan fitrah manusia yang harus dijunjung tinggi oleh siapapun. Cinta kasih yang harus "tumbuh dan berkembang" adalah cinta kasih tulus tanpa syarat kepada siapapun terutama kepada anak-anak. Cinta kasih harus dibangun melalui kultur diri dengan mendidik diri agar benar-benar tulus menyayangi dan mencintai anak-anak, dengan tidak mengedepankan kekerasan dan menjadi momok yang mencemaskan dan menggelisahkan anak. Kondisi yang menyamankan anak akan memberikan dampak positif yakni mereka akan tumbuh menjadi pribadi-pribadi yang berfungsi sepenuhnya, mampu meregulasi diri dan mampu berdaptasi dengan mudah. Oleh karenanya, cinta kasih harus dibangun oleh masing-masing pribadi dan harus mampu mendidik diri agar benar-benar membawa kemaslahatan bagi khalayak.

\section{Daftar Pustaka}

Agustinus W. D. (2017). Filsafat MoralPergumulan Etis Keseharian Hidup Manusia. Kanisius. Azam, S.R.,(2016). Penguatan Perilaku "Ngeloni Anak" Oleh Ibu-Ayah Sebagai Upaya Menciptakan Keluarga Harmonis-Seimbang Sejak Dini, Jurnal Cendekia STAIN Ponorogo Jurnal Kependidikan dan Kemasyarakatan, Vol 14. No 1.

Bahrum. (2013). Ontologi,Epistimologi,Aksiologi. Sulesana, 8(2), 36.

Gunawan, L. A. S. (2018). Problematika Jatuh Cinta : Sebuah Tinjuan Filosofis. Logos, 15(2), 130.

Kamil, I. (2020). Kementerian PPPA Catat Ada 4.116 Kasus Kekerasan Anak dalam 7 Bulan Terakhir. Kompas. https://nasional.kompas.com/read/2020/08/12/15410871/kementerianpppa-catat-ada-4116-kasus-kekerasan-anak-dalam-7-bulan-terakhir?page=all.

Kartanegara, M. (2017). Lentera Kehidupan Panduan Memahami Tuhan, Alam. Mizan.

Ketut, W., I Ketut, S. (2018). Membaca Ulang Pemikiran Gandhi Tentang Kemanusiaan, Jurnal Ilmu Sosial dan Humaniora, Vol. 7, No.1.

May, S. (2011). Love: A History (illustrate). Yale University Press. 
Media, P. D. (2020). Angka Kekerasan Terhadap Anak Tinggi Di Masa Pandemi, Kemen Pppa Sosialisasikan Protokol Perlindungan Anak. Kementerian Pemberdayaan Perempuan Dan Perlindungan Anak. https://www.kemenpppa.go.id/index.php/page/read/29/2738/angkakekerasan-terhadap-anak-tinggi-di-masa-pandemi-kemen-pppa-sosialisasikan-protokolperlindungan.

Plato. (2017). SIMPOSIUM ; Hakikat Eros, Cinta, dan Manusia. Basabasi.

Poespoprodjo, W. (1999). Filsafat Moral Kesusilaan dalam Teori dan Praktik. Pustaka Grafika.

Salam, B. (2000). Etika Individual, Pola Dasar Filsafat Moral. Rineka Cipta.

Schultz, D. (1991). Psikologi Pertumbuhan Model-model Kepribadian Sehat. Kanisius.

Sugiyono. (2011). Metode Penelitian Kuantitatif, Kualitatif dan R\&D. Alfabeta.

Wariati, N. L. G. (2019). Cinta dalam Bingkai Filsafat. Sanjiwani: Jurnal Filsafat, 10(2), 112. https://doi.org/10.25078/sjf.v10i2.1506

Wirartha, I. M. (2006). Metodologi Penelitian: Sosial Ekonomi. CV Andi Offest.

W. Poespoprodjo. (1997). Aktualisasi Filsafat IImu Ke Arah Kemasakan Praktek dan Pengelolaan IImu, dalam Baharuddin Salam: Logika Materiil (Filsafat IImu Pengetahuan). Rineka Cipta.

Yanti, D. (2017). Konsep Akal dalam Perspektif Harun Nasution. INTELEKTUALITA, 6(1), 51-62. https://doi.org/10.19109/intelektualita.v6i1.1300.

Chabibi, M. (2019). Hukum Tiga Tahap Auguste Comte dan Kontribusinya terhadap Kajian Sosiologi Dakwah. NALAR: Jurnal Peradaban Dan Pemikiran Islam, 3(1), 14-26. https://doi.org/10.23971/njppi.v3i1.1191.

Dewantara, A. W. (2019). Filsafat Moral: Pergumulan Etis Keseharian Hidup Manusia. Kanisius.

Mustafa, M., \& Talib, A. (2011). Konstruksi Filsafat Nilai: Antara Normatifitas Dan Realitas. Alauddin University.

Nasution, M. S. A., \& Haris, R. M. (2017). Filsafat IImu. Rajagrafindo Persada.

Nugroho, R. A. (2019). Konsep kebahagiaan menurut Thomas Aquinas (dalam summa theologiae i-ii, qq. 1-5) [Universitas Katolik Widya Mandala Surabaya]. http://repository.wima.ac.id/id/eprint/18590.

Sahadewa, N. W. (2013). Konsep Manusia Menurut Mohandas Karamchand Gandhi. 23(1), 120. https://doi.org/doi.org/10.22146/jf.13154. 